ISSN 1518-3483

Licenciado sob uma Licença Creative Commons

\title{
Desafios da formação de professores
}

\author{
Teacher's education the challenges of
}

\author{
Desafíos de la formación docente
}

\section{Clarilza Prado de Sousa*}

Pontifícia Universidade Católica de São Paulo, São Paulo, Brasil

\section{Resumo}

Entendendo que a formação do professor deve ser analisada também de uma perspectiva psicossocial, procura-se, neste texto, analisar como a construção da profissionalidade se articula em um cenário de presentismo - foco exagerado no presente - que se observa na sociedade atual. Como professores em formação, que escolheram uma profissão que tem por característica formar a geração futura, representam o futuro? Quais os valores que orientam as escolhas desses professores? Os programas de formação subsidiam a construção de projetos de futuro baseados em valores como liberdade, direito, justiça social? . A subjetividade do professor/aluno é considerada durante o processo de formação? Considerando que a profissão do professor se define no compromisso com a formação do futuro do aluno e da sociedade, negar a possibilidade de preparar para o futuro é negar sua profissão.

Palavras-chave: Dimensão psicossocial do currículo de formação docente. Presentismo. Projeto de futuro. Representações sociais. Subjetividade.

* CPS: PhD, e-mail: clarilza.prado@uol.com.br 


\begin{abstract}
Considering that the teacher training should also be analyzed from a psychosocial perspective, we seek to, in this paper to analyze how the construction of pressionalism is articulated in an presenteeism scenario-exaggerated focus on the present-which can be seen in today's society. How student teachers, who have chosen a profession that has the characteristic form the future generation represent the future? What are the values that guide the choices of these teachers? Training programs subsidize the teacher / student to build projects of future based on values such as freedom, law, social justice. How the subjectivity of the teacher is considered in training teachers in a formation? Considering that teaching profession is defined in the commitment to the formation of the future student, denying the possibility of preparing for the future is to deny their profession.
\end{abstract}

Keywords: teacher's education. Presenteeism. Project of future. Social representations. Subjectivity.

\title{
Resumen
}

Entendiendo que la formación del profesorado también debe analizarse desde una perspectiva psicosocial, este texto tiene como objetivo analizar cómo la construcción de profesionalismo se articula en un escenario en que se centran en la presente por demasiado - que se puede observar en la sociedad actual. Como los maestros en formación, que han elegido una profesión que tiene como característica formar la generación, representan el futuro? ¿Cuáles son los valores que guían las decisiones de estos maestros? Los programas de formación subvencionan la construcción de proyectos de futuro basado en valores como la libertad, el derecho, la justicia social. La subjetividad del maestro / estudiante es considerada durante el proceso de formación? Mientras que la profesión docente se define en el compromiso con la configuración del futuro del estudiante de la sociedad, negando la posibilidad de prepararse para el futuro es negar su profesión.

Palabras clave: Formación del profesorado. Proyecto de futuro. La representación social. Subjetividad. 


\section{Introdução}

A discussão da formação inicial de professores é uma tarefa política, técnica e exige um conhecimento não somente da natureza das atividades exigidas pelo docente, mas, também, a compreensão do espaço histórico e social onde o professor realiza suas atividades.

Formar o professor, um professor competente, tem sido um desafio que estamos enfrentando continuamente. É verdade que se tem avançado em algumas das dimensões as quais envolvem a formação docente, é preciso reconhecer. As pesquisas indicam perspectivas e contribuições teóricas relevantes quando se observa um período histórico mais longo, mesmo quando se vivencia processos de grande retrocesso na área educacional.

No entanto, o progresso em educação é lento e exige, de uma forma geral, quase uma década para se ter uma avaliação dos avanços, das correções e das superações das dificuldades, quando elas são bem conduzidas. Mas se os avanços se mostram lentamente, os processos de correção, as medidas de intervenção políticas e pedagógicas devem ser rápidas, sob pena de se perder as conquistas já efetivadas.

Há, no entanto, muitos desafios a serem encarados quando se analisa a formação inicial de professores. O presente texto, modestamente, faz uma seleção de alguns deles, aqueles que professores comprometidos teriam condições, fundamentos e experiência para enfrentá-los. Parte-se da compreensão que a formação do professor deve ser analisada também de uma perspectiva psicossocial, assim, procura-se discutir como a construção da profissionalidade se articula em um cenário de presentismo ${ }^{1}$ que se observa na sociedade atual. Como professores em formação, que escolheram uma profissão que tem por característica formar a geração futura, representam o futuro? Quais os valores que orientam as

1 Embora o termo presentismo venha sendo utilizado por autores brasileiros da Psicologia Organizacional e do Trabalho como sinônimo de presenteísmo, em inglês (presenteeism) e em francês (présenteism) significa estar presente no trabalho, mas ter baixa produtividade em virtude de um adoecimento físico ou psicológico, enquanto que presentism (inglês) ou présentisme (francês) significa um foco exclusivo e exagerado no presente, uma sensação de que somente o presente existe que não existe passado nem futuro (HARTOG, 2013). 
escolhas desses professores? Como a subjetividade desses professores se manifesta diante de diferentes experiências de alteridade, quando os outros são percebidos como mais ou menos semelhantes a eles mesmos? Como os estudos das representações sociais podem contribuir para aprofundar todas essas questões propostas?

Essas questões, que uma dimensão psicossocial da formação de professores suscita, serão aqui discutidas, a partir de quatro desafios que pretenderam sistematizar os questionamentos psicossociais.

1) Desafio da análise do contexto psicossocial em que se dá a formação e mesmo de se contrapor a ele;

2) Desafio de promover o reencantamento de valores que oriente uma formação comprometida com a qualidade do exercício profissional;

3) Desafio de promover uma formação que tenha como prática os valores que se espera que futuro professor tenha e desenvolva, isto é, de uma formação baseada na reciprocidade;

4) Desafio de promover o desenvolvimento da subjetividade, contando com a contribuição da análise representações sociais, como forma de promover a formação do sujeito-professor.

\section{Desafio da análise do contexto psicossocial em que se dá a formação}

Orientar professores em um processo de formação educativa exige oferecer a eles uma análise crítica do contexto em que irá realizar sua tarefa. Significa dizer que formadores de políticas de formação e currículo de cursos devem ter presente o cenário no qual se insere esta formação.

Qual contexto em que se desenvolve hoje a formação do professor? Qual o cenário social atual?

Uma das características de que falam autores que descrevem o cenário da sociedade atual como Wieviorka (2015), Alain Touraine (2013), Jodelet (2009), Bauman (2007), Taguieff (2004) é o presentismo que vem conformando as sociedades. 
Entende-se esse presentismo como típico de uma sociedade voltada para a atualidade imediata, sem busca de futuro, principalmente orientada pelo mercado. Como afirma Wieviorka (2015, p. 13), esse presentismo se revela "muitas vezes em apelo a uma idade de ouro mítica, como se tivéssemos bem e melhores em outros tempos "como quando ouvimos afirmar: A escola era tão boa na minha época (Não importa que não fosse para todos e que afinal não fosse tão boa assim. O passado é assim rememorado somente para deplorar sua perda e reforçar a decadência atual. O presentismo, ignorando também o futuro, define um cenário de sociedade sem futuro, ou em que a busca deste está presa "no cinismo das regras do mercado, enquanto que reinam as injustiças e as desigualdades que acabam produzindo mais violência" (WIEVIORKA, 2015, p. 12).

É um cenário social em que, como afirma Bauman (2007), tudo é ou será liquido, fluído, urgente e incerto e no qual, portanto, os laços entre os seres humanos serão cada vez mais frágeis.

Também a esse propósito, nos alerta Alain Touraine (2013), frente ao enfraquecimento das normas morais e sociais, um futuro desconhecido angustiante, nos rendemos ao dinheiro e somos guiados por vantagens econômicas sem nos preocupar com o social e sem pensar no futuro.

E aí está justamente o maior desafio. Sem atribuir sentido à construção do futuro, como desenvolver a profissão de professor, considerando que o propósito que mobiliza e define essa profissão é formar a geração futura?

A perda de um sentido, o déficit de orientação, a incapacidade de nos orientar, de nos projetar em relação ao futuro não é, no entanto, um fenômeno brasileiro. É mundial e vem sendo descrito nas Américas, na Europa, na China, dentre outros países.

Há ainda que observar que, nesse contexto, as mídias e os políticos têm tido um papel importante de desconstrução de sentidos e de fomento da desesperança. Os debates promovidos por eles não buscam reconstruir processos de humanização ou construção de sentidos. $\mathrm{O}$ jogo da mídia e dos políticos atuais tem levado a reações emocionais, no máximo de indignação e produzindo ódios e radicalismos em nada propícios 
para quem quer buscar alternativas de futuro que conduz a um processo de humanização.

Por onde começar? Como recomeçar? Como nós educadores criamos significado e sentido para a nossa função educativa? Como formar professores que possam fazer diferenças e construir o futuro com seus alunos?

O desafio que tal situação apresenta é anterior mesmo a definição de qual futuro que se quer, que se deseja ou que é necessário. Analisar criticamente esse contexto é fundamental e antes de se propor direção a seguir. A resposta a essa questão não pode resultar em um conjunto de estratégias tecnológicas, ou posições idealistas ou mesmo mudança da estrutura do currículo de formação de professores. Mesmo estando de acordo com a necessidade da mudança da formação atual de professores, sua efetividade passa pela compreensão da sociedade atual, pelos sentidos e significados que vem assumindo o mundo social na ação educativa, ou pela falta deles. Passa, também, pela compreensão das representações de professores sobre sua profissão e que sustentam suas tarefas cotidianas, a compreensão de como o professor dá conta de planejar a sua relação com os alunos, com a escola, consigo mesmo e pelo desafio de promover o reencantamento de valores de um formação que promova a esperança e promova a construção do futuro.

\section{O desafio de promover o reencantamento de valores de uma formação que promova a esperança e a construção do futuro}

\section{Como enfrentar este desafio?}

Wierviorka (2015), ao discutir o contexto social, propõe a retomada da ideia de elo social - repensar do futuro enquanto projeto. Afirma o autor, que a chamada crise não se resolverá com a volta a um sistema anterior. Não há, portanto, pensamentos mágicos. O caminho para retomar a crença no futuro exigirá se distanciar de discursos políticos e de uma comunicação midiática que prega a destruição, que nega a construção social democrática e dialogada de alternativas de futuro, apoiando-se 
em processos de radicalização que reproduzem a perda de sentido de nossa época.

A saída deste caminho, desta trajetória sem direção, exigirá uma grande mudança para nós educadores. Será necessário o reencantamento pelos valores (WIERVIORKA, 2015), procurando um envolvimento maior com os problemas da escola, da formação. É neste contexto que poderse-á construir processos de formação de professores significativos e voltados para o futuro. O pensamento do formar para quê e por quê recoloca os formadores de professores e aos próprios professores em formação no caminho da prática social da busca de sentido, da luta por uma qualidade de educação. A qualidade da educação assim definida que prevê, além da universalização da aquisição de saberes, a busca da construção de uma sociedade justa e humanizada em que haja promoção da solidariedade.

O que se quer ressaltar é que retomar valores é redefinir orientação. É reagir contra o relativismo, contra a fluidez de cada indivíduo, de cada país, de cada comunidade. Aceitar a transcendência dos valores é reagir contra a crítica reacionária que adota os relativismos que procura confundir a aceitação dos valores culturais de cada grupo social com a relativização da liberdade, do direito e da justiça.

A qualidade da educação neste cenário deve ser definida tanto pelo direito à aquisição de saberes, quanto pela vivência de valores fundamentais. Somente quando se tem os valores como metas será possível encontrar um motivo por que lutar, iluminar o caminho em busca de um futuro - para mim, para você, para o professor, para o aluno, para o país, para a humanidade.

E como afirma Gimeno Sacristán (1999, p. 181), a "educação serve não só para reproduzir realidade, mas para reconstruir a tradição que a compõe a cultura, ou as culturas, e alcançar um ideal de vida que é o desafio do futuro". Portanto, enfrentar esse desafio envolverá: lutar pela construção de um futuro e escolher os valores que deverão orientar essa luta.

A escolha de valores está dada pela Lei de Diretrizes e Bases quando estabelece no artigo 2 . : 
A educação, dever da família e do Estado, inspirada nos princípios de liberdade e nos ideais de solidariedade humana, tem por finalidade o pleno desenvolvimento do educando, seu preparo para o exercício da cidadania e sua qualificação para o trabalho (BRASIL, 1996).

A importância de tomar tais valores como orientação da ação de formação é a única possibilidade de construir uma civilização e de edificar uma sociedade. Afirma Aziza Bennani (2004, p. 31)

O mundo actual privilegiou o desenvolvimento de uma dimensão material, sacrificando muitas vezes, no altar do deus do progresso material, numerosos valores morais e espirituais. Dados econômicos, políticos, sociais, culturais ou educativos importantes evoluíram ou mudaram mesmo, de modo que a nossa visão do mundo, os nossos valore os nossos esquemas ultrapassados, nem sempre nos deixam adoptar as soluções apropriadas a problemáticas cruciais. Além disso, nem sempre conseguimos evitar a ruptura entre, por um lado, os nossos valores e as nossas culturas e por outro, a economia global, os nossos valores e as nossas culturas e, por outro, a economia global, as regras de mercado e as tecnologias novas que, embora muito úteis nos invadem. Foi criado um hiato entre os dois polos essenciais da nossa experiência a vital. Devido a isso, os particularismos culturais e as ideologias religiosas, muitas vezes desviadas do seu sentido verdadeiro, cada vez se impuseram mais como resposta única. Daí a necessidade de reforçar o nosso sistema de valores, de "tentar edificar a sociedade dos espíritos, depois de termos criado a sociedade das nações" como escreve Jerome Bindé em Les Clé du XXIo siécle.

É evidente que se tem clareza das dimensões e limites do impacto da escola e do docente no contexto atual e que é preciso não supor suas possibilidades para além do que seria pertinente. Conforme alertam Forster e Leite (2014), embora a discussão sobre formação de professores enfrente desafios e dilemas compatíveis com as exigências dos tempos atuais, tem-se ampliado a "diversidade de questões que envolvem esse tema, tornando-o abrangente e relacionado a diferentes âmbitos da 
educação, muitas vezes visto como panaceia para os problemas da educação e da sociedade" (p. 868).

Restringindo, então, o limite da ação ao possível, ao que se encontra no âmbito de nossa atuação, pode-se propor que o desafio de se contrapor à falta de sentido social que se revela no cenário de nossa época atual, de promover uma formação de professores voltada para o futuro, para a educação de cidadãos comprometidos com valores como liberdade, direito, justiça social, inicia-se pela proposição de uma formação inicial, com o desenvolvimento de uma prática curricular no ensino superior que tenha como prática os valores que pretende desenvolver. Isto é, uma formação baseada na reciprocidade.

\section{Desafio de promover uma formação que tenha como prática os valores que se espera que futuro professor tenha e desenvolva, isto é, de uma formação baseada na reciprocidade}

É preciso garantir reciprocidade na formação do professor. O sujeito professor é considerado desencarnado de sua trajetória, alienado das condições sociais. O respeito que deve manter diante das diferenças não é vivenciado em sua formação, em sua atuação. Pode-se afirmar mesmo, que a formação neste sentido está preparando-o para atuar em um sistema de ensino que consegue imaginar sua atuação desarticulada das condições sócio-históricas e culturais.

Os dados de adoecimento docente, as condições salariais, as condições vivenciadas na escola deixam clara esta perspectiva. Não há como fazer escola sem docente, mesmo o ensino à distância exige muito mais ainda do professor. Mudança se faz com o professor e independente do professor. Esta visão de professor que se formaria independentemente de um contexto reproduz uma expectativa dos governos de que será possível desenvolver a qualidade da educação sem considerar as condições e contingências que definem esta profissão.

O que se pretende afirmar é que a formação do docente na Educação Superior, ou mesmo em outros espaços de formação, precisaria 
estar mais próxima da realidade social, compreendendo as condições culturais, históricas e sociais dos formandos de maneira a oferecer vivências de boas práticas de humanização, permitindo-os construir estratégias e alternativas de como enfrentar os problemas da escola em que irão atuar.

Enfrentar este desafio da formação garantindo ao licenciando e ao professor em exercício o reencantamento dos valores e oferecendo reciprocidade na formação, significa, por exemplo, promover o respeito por meio da realização de práticas respeitosas, promovendo o acesso de todos ao conhecimento, por meio de um ensino que reconhece a trajetória de cada professor em formação e possibilita condições de superação. Isso vai exigir que a formação considere o processo de constituição da subjetividade do aluno/professor em formação. Considerar a subjetividade pressupõe afirmar a necessidade do professor, na formação, ter condições de encontrar na profissionalização o espaço que o constitui como sujeito e possibilite a ele compreender o papel do outro na construção de sua profissionalidade.

Como iniciar esse processo? Como atuar com o sujeito/professor em um ensino que tem se mostrado objetivado, naturalizado, sem espaço para as reflexões pessoais, para construção de valores? O desafio a ser enfrentado é o promover o desenvolvimento da subjetividade em um processo de formação docente que o permita compreender que ele, enquanto sujeito, se constitui em uma relação dialética com a realidade, em que a presença do outro é constituidora de sua profissionalidade.

Desafio de promover o desenvolvimento da subjetividade, contando com a contribuição da análise representações sociais, como forma de promover a formação do sujeito-professor

A possibilidade de compreensão de sua existência, de estar no mundo se constituindo na experiência, é um ponto fundamental na formação. É essa possibilidade que levará o professor a rejeitar uma visão de poder ser um indivíduo isolado, "um átomo social", para ser um sujeito que compreende-se como construído e reconstruído pelo tempo, gerações e gerações, e que não pode "ser suposto como em um estado de solipsismo” (JODELET, 2009, p. 693). 
A educação, quando perde esta perspectiva, abandona a visão holística e integrada, perde a visão do sujeito como uma constituição. Em uma perspectiva psicossocial, o sujeito - e aqui estamos precisando o sujeito professor - deve ser compreendido e se conhecer nas condições sociais em que atua, entendendo, além disso, quais são os saberes que possibilita a ele ser um sujeito melhor qualificado e atuando com consistência e firmeza, lembrando como afirma Pereira (2013, p. 843) que o professor

[...] na sua posição, precisa desenvolver a competência do discernimento para saber que aquilo que sabe e que acredita, ao mesmo tempo que aquilo que lhe dá consistência e firmeza, é aquilo que evidencia o limite do seu conhecimento e o limite da sua posição na realidade que o circunda e o circunscreve.

É nesse sentido que Gonzáles Rey (2012) afirma que, o primeiro passo em um processo de formação é entender suas representações, os sentidos e significados que se ativam nos diferentes espaços sociais e que o professor atribui ao outro. E o outro aqui é o aluno, mas não somente ele, colega, a escola, o outro

[...] não é apenas o dessemelhante - o estrangeiro, o marginal, o excluído - cuja presença presumivelmente incomodaria (por definição), mais ou menos. É também o termo que falta, o complementar indispensável e inacessível, aquele imaginário ou real, cuja evocação cria em nós a sensação de uma incompletude ou o impulso de um desejo, porque sua não-presença atual nos mantém em suspenso e como que inacabados, na espera de nós mesmos. Como, neste caso torna-lo presente? Como "existir o outro e juntando-se a ele, substituir pela plenitude de uma imediata e total presença o vazio de sua ausência? (LANDOWSKI, 2002, p. XII).

Reafirmando, o sujeito aqui referido, em processo de formação não pode ser visto como uma mônada que agrega características naturais, mas um sujeito capaz de compreender a produção de sua subjetividade como um fenômeno psicossocial. 
E nesse sentido entendemos subjetividade como a forma que o sujeito se insere no mundo e que também traduz as relações que construímos em nosso processo de alteridade. Entendendo que a alteridade que desenha as diferentes relações que o sujeito estabelece com o outro, constituindo sua subjetividade, deve ser compreendida e desenvolvida na formação de professores. Como me constituo professor, como desenvolvo minha subjetividade? Ou melhor, quem é o outro ou os diferentes outros que me definem como professor?

A visão individualista de sujeito, construída no século XIX e importada para a Educação, produziu a construção de uma subjetividade que procura obscurecer a alteridade. A formação de professor exige um voltar-se para a compreensão de si mesmo a partir dos diferentes outros que constituem sua subjetividade. Esta não é uma tarefa introspectiva, é uma ação ativa de compreensão do mundo. Não é, portanto, uma ação de volta para si mesmo, fechada em si mesmo. Formar subjetividade envolve compreender suas atitudes, interpelar seus sentimentos e voltar sobre si mesmo como se fosse o outro.

Logo, faz-se necessário o desenvolvimento de uma formação que tenha como prática, por um lado, o exercício dos valores que se pretende desenvolver, ou seja, formar o professor para atuar e exigir do sistema de ensino as condições e contingências que garantiriam a qualidade de sua atuação. Por outro lado, formar o professor para compreender a presença do outro na constituição de sua profissão e de sua subjetividade, ou, por outras palavras, compreender as diferentes vozes que se instalam em sua subjetividade, a partir em processo de reflexão ativa e não fechada em si mesmo.

Ainda nesta perspectiva, Jodelet (2009) afirma que, para compreender as vozes que se instalam na subjetividade, representativas de diferentes outros e das práticas sociais, não se pode prescindir das representações sociais que constituíram esta subjetividade. Para a autora, as representações sociais se estruturam e se constituem em três esferas de pertença: a subjetiva, a da intersubjetividade e a da transubjetividade, dependendo do espaço social onde se realizam as interações. 
Com o propósito de oferecer uma visão mais clara da interligação das representações sociais com as esferas de pertença, Jodelet (2009) cria uma metáfora com um diagrama apresentado na figura 1.

Figura 1: As esferas de pertença das representações sociais

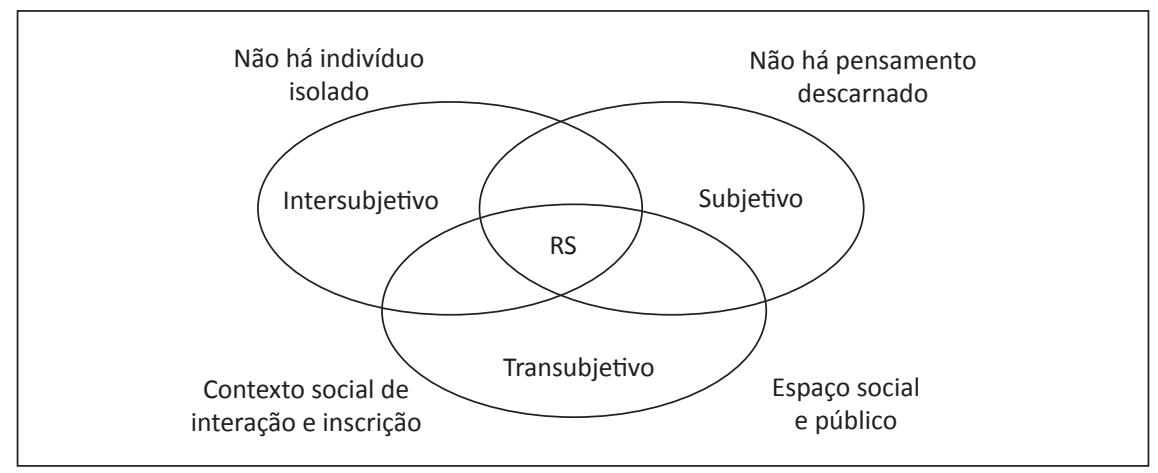

Fonte: Jodelet (2009, p. 695).

Considerando que toda representação social é sempre de um sujeito, se refere a um objeto, se realiza em um dado espaço social, em uma dada contingência histórica (MOSCOVICI, 1961, 1976; JODELET, 2001), pode-se afirmar que estas esferas de pertença definem complexidades de cada nível de abrangência da subjetividade.

Assim, a esfera de pertença subjetiva refere-se aos processos de produção de representações a partir dos processos que operam no nível dos indivíduos eles-mesmos, isto é, produzidas pelos sujeitos em sua cotidianidade e que tem a ver com sua trajetória pessoal e com a inserção social dos diferentes grupos sociais de pertença.

A esfera de pertença da intersubjetividade remete às situações em que as representações assumem a direção e definem a orientação das interações entres sujeitos.

A esfera de pertença da transubjetividade perpassa as duas esferas (subjetiva e intersubjetiva) e alcança o espaço social público e os sistemas de poder. Esta é uma esfera em que a contribuição psicossocial 
das representações sociais tem sido pouco pesquisada, principalmente no Brasil, e teria condições de contribuir para compreender como processos de normalização de modelos de subjetivação promovidos pelo Estado e pela sociedade, na formação de educadores, têm produzido subjetividades de docentes que excluem o outro, construídas a partir de uma visão de sujeito/professor desencarnado de sua trajetória, alienado das condições sociais, desenvolvendo uma visão política que contribui para formar professores os quais não se reconhecem como protagonistas individuais da ação docente.

Os estudos de representações sociais no campo educacional foram e têm sido muito mais amplos do que os prognósticos de Gilly (2001) quando procurava identificar as possibilidades e contribuições que esta teoria poderia oferecer à educação. Para os pesquisadores da área de educação que compreendem a função básica deste campo como aquela destinada à transformação do outro para o desenvolvimento social, o encontro com a teoria das representações sociais apresentou um potencial heurístico de grande valor. Os estudos da teoria das representações sociais chamam ainda a atenção de que a formação do professor não pode ser realizada sem considerar a urdidura em que os Sujeitos que são "objetos" da ação docente e aqueles que são promotores dessa ação, tecem suas práticas.

Em 2013, os pesquisadores que compõem o Centro Internacional de Estudos em Representações Sociais e Subjetividade-Educação, da Fundação Carlos Chagas (CIERS-Ed/FCC), procuraram analisar como as representações sociais estavam sendo trabalhadas na área de educação. Assim, foram levantadas junto ao Banco de Teses/Dissertações da CAPES no triênio 2010/2011/2012, todas as teses/dissertações defendidas no Brasil que tinham no título ou definiam como palavra-chave "representações sociais". Em seguida, foram selecionadas aquelas defendidas na Área de Educação. Destas, foram levantados em seus resumos: os objetivos, as metodologias usadas, os possíveis desafios, problemas e contribuições feitas. O estudo identificou, no triênio 2010/2011/2012, um total de 834 dissertações de mestrado e 222 teses de doutorado defendidas em todas as áreas e que assinalaram no título "representações sociais" ou que 
registraram o termo entre suas palavras chaves. Deste montante, cerca de $38,6 \%$ (322) das dissertações e 39,6 \% (88) das teses foram defendidas na área de educação.

$\mathrm{Na}$ análise destes estudos, fica claro que os autores reforçam as possibilidades dos estudos em representações sociais, como instrumental teórico para compreensão das relações que se constituem na prática da escola, como potencial político na identificação de um Sujeito-professor contextualizado em uma dimensão psicossocial. Evidenciaram a complexidade da representação indicando as múltiplas ou famílias de representações sociais que se inter-relacionam, desvelaram a contribuição do contexto, indicaram as possibilidades para subsidiar a formação do professor e apresentando pistas para a transformação de práticas.

Concluindo, os desafios da formação do professor, foram aqui apresentados considerando os seguintes argumentos:

1) o cenário atual indica um presentismo que não se revela somente no Brasil, mas é observado nas Américas, na Europa e na China. Tal presentismo nega as condições de um projeto de futuro;

2) a profissão do professor tem como propósito a formação do futuro do aluno, da sociedade. Logo, negar a possibilidade de preparar para o futuro é negar sua profissão.

Como alternativa, temos que:

1) o reencantamento dos valores: condição necessária para a formação do professores sob pena de negar a sua profissão. A LDB define os valores que devem orientar e conduzir a educação nacional. Art. $2^{\circ}$ LDB 9.394/1996 (BRASIL, 1996);

2) os valores indicam o norte, fornecem orientação, iluminam o caminho, e indicam por que lutar, ou seja, constituem a base de um projeto de vida;

3) o projeto de futuro do professor passa necessariamente pelo reconhecimento da alteridade, já que a especificidade da profissão de professor é a interatividade, tal como colocado por 
Tardif e Lessard (2005) e essa alteridade é constituinte de sua subjetividade;

4) a subjetividade do professor se constitui na sua relação com o outro-aluno, o outro-colegas de trabalho, o outro-família e comunidade onde a escola está inserida, mas essa alteridade tem como pano de fundo as representações sociais desses outros e os valores que orientam seu projeto de vida.

\section{Conclusão}

Para finalizar, compartilham-se algumas das questões/desafios que as reflexões aqui apresentadas se impuseram e que foram transformadas em questões de pesquisa, que estamos desenvolvendo. Pretende-se com ela caminhar um pouco mais no sentido de aprofundar a discussão dos desafios apresentados².

Como professores em formação, que escolheram uma profissão que tem por característica formar a geração futura representam o futuro?

Quais as representações e valores que orientam as escolhas e julgamentos desses futuros professores diante de diferentes contextos profissionais?

Como a subjetividade desses professores se manifesta diante de diferentes experiências de alteridade, quando os outros são percebidos como mais ou menos semelhantes a ele mesmo?

Os currículos dos cursos de licenciatura subsidiam a construção de projetos de futuro baseados em valores como liberdade, direito, justiça social, tendo em vista a constituição da subjetividade dos estudantes, futuros professores em formação?

2 As questões aqui apresentadas fazem parte de projeto de pesquisa aprovado pelo CNPq que está sendo desenvolvido no âmbito NEARS - Núcleo de Estudos Avançados em Representações Sociais da PUCSP. 


\section{Referências}

BAUMAM, Z. Le prêsent liquide. Paris: Seuil, 2007.

BENNANI, Aziza. Introdução ao livro Para onde vão os valores ? Titulo Original Où vont les valeurs?Direção Jérome Bindé. UNESCO, 2004. Direitos reservados em língua portuguesa: Instituto Piaget 2006.

BRASIL. Lei n ${ }^{\circ}$ 9.394/1996, de 20 de dezembro de 1996. Estabelece as Diretrizes e Bases da Educação Nacional. Diário Oficial da União, Brasília, DF, n. 248, 23 dez. 1996. Disponível em: 〈http://www.planalto.gov.br/ccivil_03/leis/19394.htm〉. Acesso em: 15 set. 2016.

FORSTER, M. M. dos S.; LEITE, T. C. Formação continuada de professores: da parceria entre universidade e escola ao protagonismo e reconhecimento do trabalho docente. Revista Diálogo Educacional, Curitiba, v. 14, n. 43, set. 2014.

GILLY, M. As representações sociais no campo da Educação. In: JODELET, D. (Org.). As Representações Sociais. Rio de Janeiro: EdUERJ. 2001. p. 321-341.

GIMENO SACRISTÁN, J. Poderes instáveis em educação. Porto Alegre: ARTMED Sul, 1999.

GONZALEZ REY, F. O social na psicologia e a psicologia social: a emergência do sujeito. Trad. Vera Lúcia Mello Joscelyne. Petrópolis, RJ: Vozes, 2012.

JODELET, D. Representações sociais: um domínio em expansão. In: JODELET, D. (Org.). As representações sociais. Trad. Lilian Ilup. Rio de Janeiro: EdUERJ, 2001. p. 17-44.

JODELET, D. O movimento de retorno ao sujeito e a abordagem das Representações Sociais. Sociedade e Estado, Brasília, v. 24, n. 3, p. 679-712, set./ dez. 2009. 
HARTOG, F. Regimes de historicidade: presentismo e experiências do tempo. Trad. Andréa Souza de Menezes; Bruna Beffart; Camila Rocha de Moraes; Maria Cristina de Alencar; Maria Helena Martins. Belo Horizonte: Autêntica Editora, 2013 (edição original em francês 2003).

LANDOWSKI, E. Presença do outro. Trad. Mary Amazonas Leite de Barros. São Paulo: Editora Perspectiva, 2002.

PEREIRA, M. V. Saberes necessários ou desejados para uma docência de qualidade na educação superior. Revista Diálogo Educacional, Curitiba, v. 13, n. 40, dez. 2013.

MOSCOVICI, S. A representação social da psicanálise. Trad. Álvaro Cabral. Rio de Janeiro: Zahar Editores 1978 (Trabalho original publicado em 1961).

MOSCOVICI, S. Representações sociais: investigações em psicologia social. Trad. Pedrinho A. Guareschi. Petrópolis, RJ: Vozes, 2003.

TARDIF, M.; LESSARD, C. O trabalho docente: elementos para uma teoria da docência como profissão de interações humanas. Trad. João Batista Kreuch. Petrópolis, RJ: Vozes, 2005.

TAGUIEFF, P.-A. Le sens du progrès: une approuche historique et philosophique. Paris: Flammarion, 2004.

TOURAINE, A. La Fin des société. Paris: Seuil, 2013.

WIERVIORKA, M. Retour au sens: pour en finir avec le déclinisme. Paris, Collecition «Le monde comme il va». 2015.

Recebido: 31/08/2016

Received: 08/31/2016

Aprovado: 10/09/2016 Approved: 09/10/2016 